\title{
Differential inflation with short and long CS-US intervals: Evidence of a nonassociative process in long-delay taste avoidance
}

\author{
JOSEPH P. DECOLA and MICHAEL S. FANSELOW \\ University of Califormia, Los Angeles, California
}

\begin{abstract}
Three experiments were performed to investigate the learning process underlying the phenomenon of long-delay taste conditioning. An associative model views taste avoidance as due to a conditioned stimulus-unconditioned stimulus (CS-US) associative structure, despite the long interval interposed between the flavor and illness. A nonassociative account of this avoidance behavior posits that avoidance stems from the interaction of two nonassociative processes: habituation of neophobic avoidance to a novel taste, and the poison-induced dishabituation of this process. A postconditioning inflation manipulation was used to discriminate between these two views. It has been demonstrated that enhanced responding with a US inflation manipulation depends, in part, on a previously conditioned association. Therefore, if long-delay taste avoidance arises from nonassociative processes, an inflation manipulation should not affect conditional responding. Experiment 1 demonstrated a delay of reinforcement effect, enhanced avoidance of saccharin in the immediate/inflation group, and no effect of inflation in the delay group and sham controls. Experiment 2 revealed that this differential effect of inflation is not due to absolute differences in the strength of the avoidance response. In Experiment 3, we investigated a potential associative learning mechanism that could account for the differential inflation effect. Together, the present results support the various predictions of a nonassociative account of long-delay taste avoidance.
\end{abstract}

Garcia, Ervin, and Koelling (1966) reported that rats demonstrate substantial avoidance of a novel taste paired with illness despite a long delay between these events. Like other conditioning preparations, taste aversions show a delay of reinforcement effect; increases in the taste-poison interval result in reduced avoidance. However, considerable avoidance is observed following delays of hours between the conditioned stimulus (CS) and unconditioned stimulus (US) (Garcia et al., 1966; Revusky, 1968; Smith \& Roll, 1967). Typically, a delay in the order of seconds or minutes is sufficient to attenuate learning in other conditioning paradigms (see, e.g., Mackintosh, 1983). This unique feature of taste aversions led to the development of several theories that postulate a specialized associative mechanism in the taste conditioning system that can accommodate long CS-US intervals (Garcia et al., 1966; Garcia, McGowen, \& Green, 1972; Rozin \& Kalat, 1971).

We thank John Garcia and Denis Mitchell for their critical comments and helpful suggestions during the development of these experiments, Lance Fuchs for his assistance in the execution of this work, and Steven Maren for assistance with the manuscript revision. In addition, we thank Jacqueline Wynn and the students of the animal learning laboratory course at UCLA for the execution of initial pilot experiments. This research was supported by a grant from the National Institute of Mental Health (MH39786) to M.S.F. Correspondence concerning this article should be addressed to J. P. DeCola, Department of Psychology, University of California, Los Angeles, CA 90095-1563.

-Accepted by previous editor, Vincent M. LoLordo
A number of hypotheses have been proposed to explain this delay of reinforcement gradient in taste-aversion learning. These various positions can be divided into two basic categories, based on their assumptions concerning the underlying process responsible for longdelay learning. One type of account assumes an associative mechanism; the other assumes that the process is strictly nonassociative. Many of the associative accounts also recognize the role of nonassociative processes inherent in taste aversions. Phenomena such as neophobia, sensitization, and habituation have been incorporated into various aspects of these models. However, all the associative accounts hold that taste avoidance following a delayed pairing is ultimately a function of the same associative mechanism that operates with an immediate pairing. In addition, they share the view that despite the unusual temporal parameters, the dynamics of the associative process may not be qualitatively different from that of other classical conditioning preparations (Domjan, 1980; Logue, 1979).

A number of different mechanisms for the delay of reinforcement effect have been proposed. One possibility was that conditioning is due to a lingering aftertaste that spans the conditioned stimulus-unconditioned stimulus (CS-US) interval (see Kalat \& Rozin, 1971; Revusky \& Garcia, 1970). Another proposal envisioned a slow decay process in which the CS representation passively decays over the course of the delay interval. Consequently, a weaker association is formed when this attenuated CS representation is ultimately paired with illness. Alterna- 
tively, Revusky and Garcia argued that the passage of time serves solely to increase the probability that interfering gustatory events will compete with and reduce the conditioning of the target stimulus. Kalat and Rozin (1973) showed that both of these accounts are incongruent with experimental findings.

The "learned safety" theory proposed that there is an active associative process operating during the CS-US interval (Kalat \& Rozin, 1973). The animal learns that the taste is safe because illness does not follow ingestion. This view was based in part on the demonstrations that novelty of a taste is often a critical determinant in the formation of a taste aversion (Revusky \& Bedarf, 1967). Rozin and Kalat (1971) suggest that rats treat a novel food source as "potentially dangerous." Typically, rats will tend to avoid a new food and engage in limited sampling only (Barnett, 1963). The associative process proposed in the learned safety theory assumes that this innate neophobic response to new tastes is actively modified during the long interval before poisoning. During this period the animal learns that the new taste is safe. This learning then competes with or actively inhibits the formation of an excitatory association between the taste and the delayed illness. Evidence in support of this position and contrary to the predictions of the decay account has been reported by Kalat and Rozin (1973). Equivalent avoidance was observed in two groups of rats with a 4-h CS-US delay interval, despite one group receiving a second reminder taste immediately before the poison. Both of these long-delay groups showed less avoidance than did a group that received a temporally contiguous pairing of the taste and poison. Clearly, this demonstration does not support a simple nonassociative decay function, since the second presentation should have adequately refreshed a decayed CS representation. Although the active conditioned inhibition process proposed in the learned safety theory can account for this demonstration, the specific nature of this mechanism also has been challenged. Best (1975) has demonstrated that a safe exposure to a taste can also act to reduce conditioned inhibition of the preexposed taste stimulus. Learned safety theory predicts that a safe preexposure should enhance, not retard, subsequent conditioned inhibition training. Therefore, Best has suggested that taste preexposure may be more parsimoniously understood as reflecting latent inhibition rather than conditioned inhibition. Nonreinforced preexposure to a taste stimulus may simply attenuate subsequent associability through reduced attention or salience.

Clearly, the associative accounts have problems completely explaining the taste avoidance found with long taste-poison intervals. Alternatively, a strictly nonassociative hypothesis of taste avoidance has been offered that can account for the long-delay effect (Mitchell, Kirschbaum, \& Perry, 1975; Mitchell, Parker, \& Johnson, 1976; Mitchell, Scott, \& Mitchell, 1977). This account employs three nonassociative phenomena to explain the delay of reinforcement gradient: neophobic avoidance, habituation of neophobia, and the dishabitu- ating action of poison. The critical feature of this account is that the poison may function in a nonassociative manner. The usual habituation of neophobia can be attenuated or dishabituated by illness. This account, advanced by Mitchell and colleagues, relies on the finding that rats display a strong neophobic response to novel tastes (Barnett, 1963; Carroll, Dinc, Levy, \& Smith, 1975; Domjan, 1975; Richter, 1953; Rozin, 1968; Rzoska, 1953). In addition, this model incorporates the well-established finding that neophobic avoidance habituates over time or with repeated exposures (Bond \& Westbrook, 1982; Green \& Parker, 1975; Nachman \& Jones, 1974). A recent demonstration of this effect showed greater saccharin consumption on a second exposure to saccharin when there was a long interval between the two presentations (Bonardi, Guthrie, \& Hall, 1991). Poison, in the nonassociative model, acts to arrest the habituation process at a later point or simply to dishabituate neophobia.

A taste aversion established when poison immediately follows the taste results in associative learning. However, it is not clear if taste avoidance following a long taste-illness interval is due to the nonassociative processes of neophobic habituation and dishabituation or to a specialized associative mechanism (Mitchell et al., 1977). Although the dynamics of these two models are quite distinct, both make similar predictions with many conditioning procedures. The delay of reinforcement gradient and CS preexposure effects can be explained by either account. Indeed, experimental differentiation of these two accounts has proved difficult and has been the subject of considerable debate (see Garcia, 1978; Mitchell, 1977, 1978; Revusky, 1977, 1978, 1979; Riley, 1978; Smith, 1978). The aim of the present experiments was to provide a way to discriminate between these positions. This attempt employed an inflation manipulation subsequent to the initial CS-US presentation that should differentially affect associative and nonassociative processes. Rescorla (1974) has shown that postconditioning exposure to a more intense US produces an inflated conditional response to the $\mathrm{CS}$. He proposed that this modified response depends in part on an associative structure. The inflation procedure has been used as a tool to differentiate the learning processes underlying simultaneous and trace conditioning (Sherman, 1978). In the present study, it was predicted that an inflation manipulation should produce enhanced avoidance in both short and long tasteillness intervals if both procedures produce a CS-US association. Alternatively, the nonassociative account predicts a differential effect of inflation in these groups, since the assumed mechanism supporting avoidance in a longdelay group does not result in a CS-US association.

\section{EXPERIMENT 1}

The first experiment determined whether a postconditioning inflation manipulation differentially affected taste avoidance established with short and long tastetoxin intervals. Toward that aim, three groups were used: 
a sham control and two groups that received poison at different times following the taste. One of the poisoned groups received an immediate CS-US pairing, and the other had a 3-h interval interposed between these events. The following day, half the animals in each group received an inflation injection. A water-only recovery day was interposed between the inflation manipulation and the test to ensure complete recovery from the second injection and to avoid enhancement of avoidance due to possible illness-induced sensitization. This 48 -h interval between the inflation manipulation and testing should attenuate any transient illness-mediated enhancement of neophobia (Domjan, 1975, 1977). Avoidance on the test days was measured with a choice between saccharin and water.

\section{Method}

\section{Subjects and Apparatus}

The subjects were 30 adult, male, Long-Evans rats weighing between 350 and $500 \mathrm{~g}$. The rats, derived from Blue-Spruce Farms stock (Altamont, NY), were born and raised in the UCLA Psychology Department colony with a 14:10-h light:dark cycle. They were individually housed in standard, stainless steel hanging cages $(18 \times 18 \times 24)$ at 90 days of age and had ad-lib access to rat chow and water. Before the present experiment, all the animals received daily handling for 1 week and were used in a fear-conditioning experiment in which a few brief (1-sec), mild (1-mA) electric footshocks were administered. Following this treatment, the rats were moved to a different testing room, where all phases of the present study were conducted, and remained there undisturbed for 1 week before the start of this experiment.

\section{Procedure}

Water deprivation and habituation. At the start of the experiment, the rats were placed on a 23.5-h water deprivation schedule. During this 8-day adaptation period, distilled water was available for a 30-min period once a day. At approximately $1200 \mathrm{~h}$, the food hoppers were removed from the cage and replaced with clean empty hoppers. The water was presented in a $50-\mathrm{ml}$ centrifuge tube with a rubber stopper and a curved 5-cm stainless steel drinking tube with a $.3-\mathrm{cm}$ opening. The tube was inserted through the bars of the empty food hopper so that the tip of the tube extended $2 \mathrm{~cm}$ into the cage, approximately $3 \mathrm{~cm}$ above the floor and $5 \mathrm{~cm}$ from the sidewall. After this 30-min period, the tube was removed and the rat was weighed and given a mock injection with a blunt, plastic-tipped syringe. The mock injection consisted of holding the animal upright so that its ventral surface was exposed and then mildly pressing the syringe, for $5 \mathrm{sec}$, against the skin in the right, lower quadrant of the abdomen. Since a large injection volume was to be given, this regimen was used to habituate the rats to the in jection procedure and ensure successful drug delivery in the subsequent phases. The empty food hopper was then removed, and the filled hopper was returned to the cage. The centrifuge tubes were weighed before and after each drinking period to determine daily fluid consumption.

Conditioning. On Day 9, the rats were randomly divided into three groups $(n=10)$ and presented with the taste stimulus instead of water in the drinking tubes. The conditional stimulus was a $.1 \%$ $(w / v)$ solution of sodium saccharin. The groups were defined by the type and timing of the injection received following the saccharin presentation. One group served as a sham control and received a $5-\mathrm{ml} / \mathrm{kg}$ injection of isotonic saline immediately following the 30-min drinking period. A second group received an immediate $5-\mathrm{ml} / \mathrm{kg}$ injection of isotonic $(.15 \mathrm{M})$ lithium chloride
(LiCl). The long-delay group received the same volume of $\mathrm{LiCl}$, but the injection was given $3 \mathrm{~h}$ after saccharin consumption.

Inflation. Twenty hours after conditioning, all animals received a second injection of isotonic $\mathrm{LiCl}$. The volume of this injection was $15 \mathrm{ml} / \mathrm{kg}$, three times larger than the volume of the previous day's injection. Half the rats in each group received $\mathrm{LiCl}$ and half received an equal volume of saline. The conditioning and inflation procedures yielded six groups: sham/inflation, sham/no-inflation, immediate/inflation, immediate/no-inflation, delay/inflation, and delay/no-inflation. Four hours after the inflation injection, all rats received water for the normal 30 -min period. On the day following the inflation manipulation, they also received a water-only session to allow for recovery from any residual drug effects before testing.

Preference test. For the next 12 days, all rats were given a $30-$ min two-bottle choice between water and saccharin. The two solutions were presented simultaneously, in a manner similar to the other phases, with the following exceptions. The left-right bottle position was reversed on each test day. In addition, when presenting each tube, the experimenter ensured that all rats sampled briefly from both solutions. This was accomplished by inserting the left tube and removing it when the rat had sampled the solution, then quickly inserting the other tube and removing it after the rat licked the spout, and finally reinserting the two tubes into the cage simultaneously and leaving them in place for $30 \mathrm{~min}$. This method removes the contaminating influence of side preference and the possibility of a thirsty rat fixating on the first solution presented before sampling both choices. The technique was employed in all of the present experiments.

Data analysis. A percent saccharin preference score was computed for each animal on each test day with the formula, $S /(S+W) \times$ 100 , where $S$ is the amount of saccharin consumed, and $W$ is the amount of water drunk during the 30 -min test. The data from the two-bottle preference tests were evaluated in an analysis of variance. Significant main effects of group on each test day were analyzed further with a set of preplanned comparisons. The groups that did not receive the inflation injection were used to assess baseline saccharin avoidance for the immediate and delay conditions. Both the no-inflation immediate and the no-inflation delay groups were compared with the no-inflation sham control (sham/noinflation vs. immediate/no-inflation and sham/no-inflation vs. delay/ no-inflation). To evaluate the delay of reinforcement effect, the immediate/no-inflation group was compared with the delay/no-inflation group. The inflation manipulation was assessed within each conditioning group by comparing the inflation group with its no-inflation control (sham/inflation vs. sham/no-inflation, immediate/inflation vs. immediate/no-inflation, and delay/inflation vs. delay/noinflation). A rejection criterion of $p<.05$ was used for all statistics computed.

\section{Results and Discussion}

The rats increased water consumption during the baseline period from Day $1(M=11.1 \mathrm{ml})$ to Day $8(M=$ $16.73 \mathrm{ml}$ ). On the last baseline day, the mean water consumption was not different for the six groups $[F(5,24)=$ $2.12]$. The consumption of saccharin on the conditioning day $(M=12.13 \mathrm{ml}$ ) was significantly less than the amount of water drunk on the previous baseline day $[t(29)=7.18]$. This pattern suggests a neophobic avoidance of the novel solution.

The preference scores for the 12 test days are depicted in Figure 1. Saccharin avoidance on Day 1 can be seen in all four CS-US paired groups as opposed to the sham controls. A delay of reinforcement effect is seen in the 


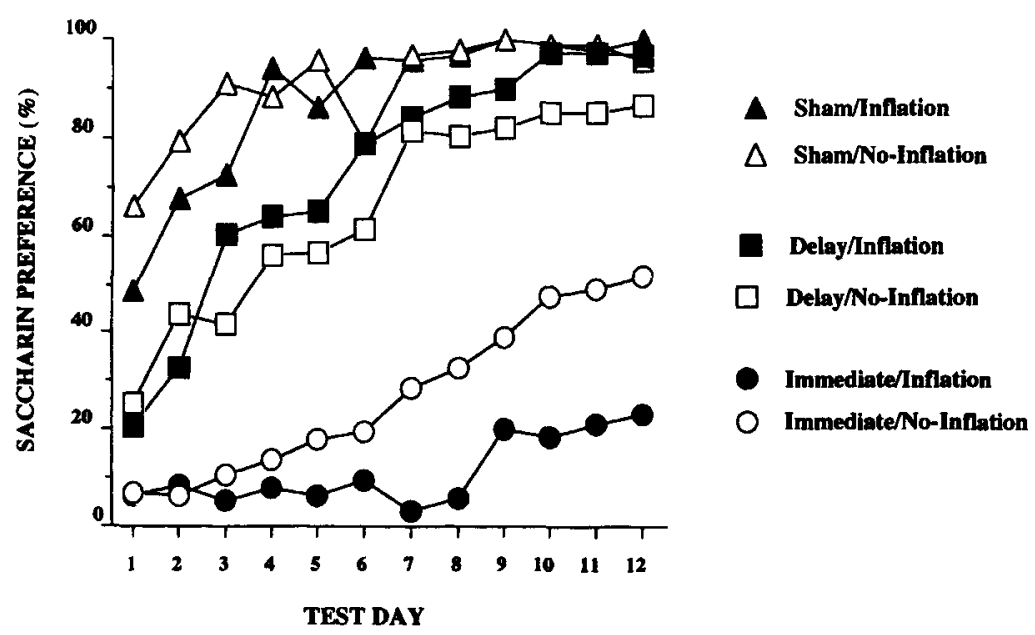

Figure 1. Mean saccharin preference during the 30-min two-bottle saccharin-water choice for the 12 test days of Experiment 1. The first word of the group designation refers to the conditioning treatment; the second word indicates the inflation condition. The filled symbols reflect animals that received the inflation dose of $\mathrm{LiCl}$, and the open symbols indicate a saline injection during the inflation phase.

greater avoidance in the immediate groups relative to the delay groups. This pattern continued across the 12 test days. Of primary interest for the present study is the obvious effect of the inflation manipulation in the immediate group, which begins to appear around Day 7. From this point to the end of the test, the immediate/inflation group demonstrated pronounced and continued saccharin avoidance in comparison with the no-inflation/immediate group. Although there is a strong inflation effect in the immediate groups, there is no evidence of an effect of the inflation manipulation in either the delaypoisoned groups or the sham controls. Moreover, it is notable that the enhanced response in the immediate inflation group persists to the last test day. This robust, long-lasting enhancement is unlikely to represent a sensitization process, especially since no enhancement is seen in the sham/inflation control group.

The pattern of group differences observed in Figure 1 is substantiated by the statistical analysis. A repeated measures ANOVA revealed a significant group $\times$ test day interaction across the 12 days of the extinction test $[F(55,264)=2.02]$. Separate ANOVAs conducted for each day indicated a significant main effect of group at each day [all days, $F(5,24)>328.25$ ]. Each of these group effects was further decomposed with the previously described set of preplanned comparisons. The immediate/no-inflation group differed significantly from the sham control, having a strong aversion on each day. The typical delay of reinforcement effect is seen in the weaker avoidance in the delay group demonstrated by a reliable difference between the delay/no-inflation and the sham/no-inflation group only on Days $1-5$. In addition, there was a reliable difference between the noinflation immediate and delay groups on all test days except Day 1.
The three comparisons that examined the impact of the inflation manipulation within each conditioning treatment indicated a differential effect of inflation among the treatments. The postconditioning inflation manipulation had no effect on saccharin preference in the sham and delay groups. There were no reliable differences between the inflation and no-inflation groups on any test day within either treatment condition. However, a significant effect of inflation appeared in the immediately poisoned animals during the second half of the extinction test. Saccharin avoidance in the immediate/inflation group was significantly greater than avoidance in the immediate/no-inflation group on Test Days 7, 8, 10, 11, and 12.

The failure to observe an inflation effect in the longdelay group is especially striking, given that we observed substantial avoidance in these animals. This result is difficult to reconcile with a simple associative model that postulates a similar process responsible for avoidance in both the immediate and the delay groups. Associative accounts view the difference in avoidance between these conditions as purely quantitative. Less avoidance in the delay group merely reflects a weaker CS-US association. Therefore, the inflation manipulation should have enhanced avoidance in both groups. However, if avoidance in the delay group is a function of nonassociative processes and a long CS-US interval does not result in a CS-US association, then inflation of the US representation should not affect performance in this group.

The inflation effect can be seen as a direct result of a changed US representation that should augment conditional responding, given an intact CS-US association. Of course, this interpretation assumes that the avoidance observed in the immediate group is due to associative 
learning and accepts the interpretation that US inflation effects require associative representations. The present experiments do not contain direct evidence for these processes but rather accept previously reported experimental evidence (e.g., Rescorla, 1974) that has demonstrated substantial support for this notion.

\section{EXPERIMENT 2}

The results of Experiment 1 demonstrate a clear difference in the effectiveness of the inflation manipulation with the immediate and long-delay procedures. As mentioned above, this finding could be incorporated by a model that assumes a nonassociative mechanism for the delay condition. However, there is an alternate interpretation of these data that does not demand a difference in learning processes. Although an associative account of long-delay conditioning presupposes an associative structure, it is possible that an inflation effect can be observed only when the associative strength exceeds a particular magnitude (see, e.g., Sherman, 1978, p. 467). Thus, it is not clear whether the differential inflation effect in Experiment 1 stems from a different learning process or is simply due to the quantitative difference in the level of saccharin avoidance following the initial poisoning. In other words, lack of an inflation effect may be an artifact of the delay of reinforcement gradient.

This possibility was addressed in Experiment 2 by equating the degree of saccharin avoidance in the immediate and delay no-inflation groups. This could have been achieved by manipulating either the number of trials or the strength of either the CS or the US. We chose to manipulate the salience of the CS, because additional US trials or a more intense US could compromise the impact of the inflation manipulation. Multiple exposures to the US in acquisition could result in habituation of the unconditioned reaction (UR) to the poison and therefore reduce the ability of the inflation injection to enhance conditioning. There are numerous examples of this type of US habituation effect in both the conditioned suppression and the taste conditioning literature. Holman (1976) demonstrated that preexposure to the US before taste-aversion conditioning reduces the ability of the US to support avoidance. This result is consistent with a UR habituation mechanism, although the experiment contained no direct measure of UR habituation during the preexposure phase. It suggests that multiple conditioning trials could produce UR habituation that reduces the impact of the inflation injection. A CS salience manipulation offers a documented relationship between stimulus intensity and avoidance strength that is predicted by both the associative and the nonassociative accounts. A decrease in saccharin concentration will result in a reduction in associative strength and conditional responding, whereas increasing the intensity will have a positive effect on associative strength. This functional relationship between taste intensity and degree of avoidance is also explicable in terms of relative changes in neophobic avoidance. A stronger saccha- rin concentration should produce a greater neophobic response than a weaker solution. Manipulations of the duration of CS exposure (Bond \& Di Giusto, 1975) and the intensity or concentration of the taste stimulus (Barker, 1976; Braun \& Rosenthal, 1976) have been shown to affect the strength of avoidance with a delayed poisoning. Indeed, both Braun and Rosenthal (1976, Experiment 2) and Barker (1976, Experiment 2) report changes in neophobic avoidance that parallel their concentration manipulation.

In Experiment 2, we employed the design and parameters of Experiment 1, except that the CS intensity for the immediate groups was reduced from .1\% to $.005 \%$ saccharin and the concentration of saccharin in the delay groups was raised to $.2 \%$. The aim was to equate the strength of saccharin avoidance in the delay and immediate no-inflation groups and observe the effect of the inflation manipulation under these conditions.

\section{Method}

\section{Subjects and Apparatus}

The subjects were 20 adult male Long-Evans rats from the same stock as that in the previous experiment. There were 5 rats randomly assigned to each of four groups. The treatment of animals prior to the start of the present procedure was identical to that described in Experiment 1.

\section{Procedure}

All the procedures were identical to those in Experiment $1 \mathrm{ex}$ cept for the omission of a sham control and a change in the saccharin concentration for both conditioning groups. The concentration was $.005 \%(\mathrm{w} / \mathrm{v})$ for the rats injected immediately after saccharin consumption, and $.2 \%(\mathrm{w} / \mathrm{v})$ for the delay group. The test phase was conducted for 6 days.

\section{Results and Discussion}

A difference in saccharin consumption was observed as a function of concentration on the conditioning day. The less intense stimulus resulted in a mean group intake of $15.3 \mathrm{ml}$; the average consumption was only $6.2 \mathrm{ml}$ for the stronger solution. This difference is in contrast to equivalent and greater consumption among all animals on the previous baseline water day $(M=$ $21.6 \mathrm{ml}$ ). This differential neophobic avoidance of saccharin follows a significant, intensity-dependent relationship $[F(1,18)=414.05]$. This difference can be attributed to the initial neophobic response to these two solutions which is a critical feature of the nonassociative interpretation. The difference in neophobia reflects the greater similarity of the weaker solution to the familiar baseline water source. This interpretation is consistent with the finding that taste salience depends on a novel/ familiar comparison (Kalat, 1974).

As can be observed in Figure 2, saccharin preference was equivalent among the four groups on the 1st day of the two-bottle test. This pattern continued to the last test day for all groups except for the immediate/inflation group. These animals demonstrated a persistent saccharin avoidance across the entire extinction test. The present conditioning parameters produced differential inflation 


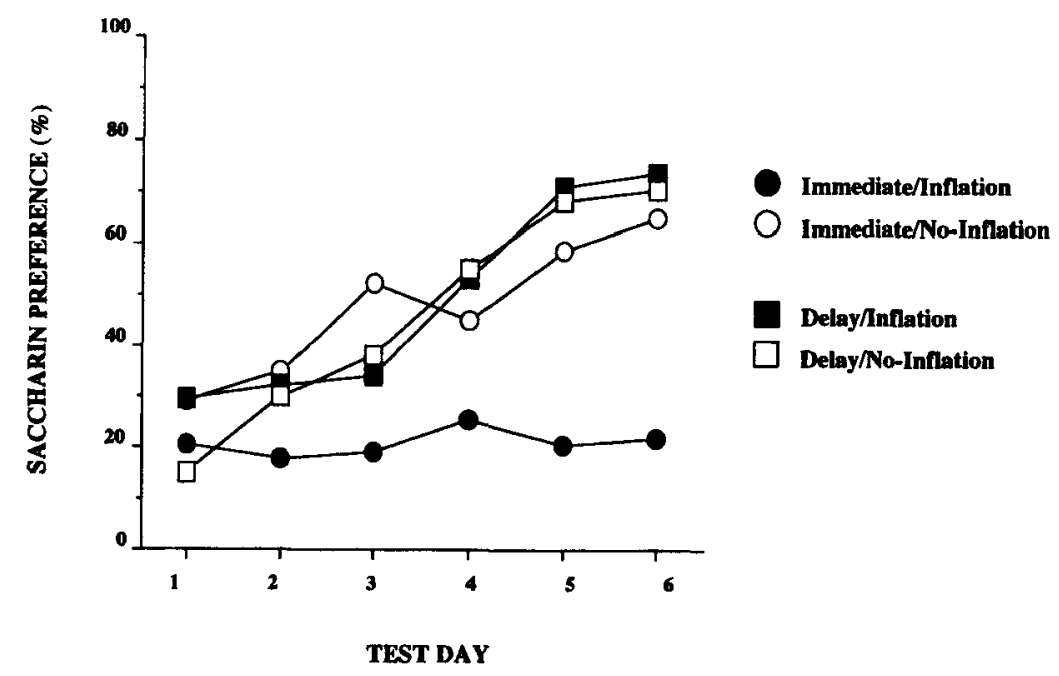

Figure 2. Mean saccharin preference across the 6 days of the saccharin-water choice test in Experiment 2. The saccharin concentration was $.005 \%$ for the immediate groups and $.2 \%$ for the delay groups.

with short and long CS-US intervals and successfully equated avoidance in the two no-inflation groups.

The repeated measures ANOVA performed to assess group differences across the 6 test days revealed a marginally significant interaction of these factors $[F(15,80)=$ $1.63, p=.08]$. Although this interaction did not meet our stated criterion for rejection, the pattern of main effects among the one-way ANOVAs performed at each day revealed a differential effect of group, and the set of analytical comparisons chosen was derived from an a priori hypothesis (Keppel, 1982, p. 106). These analyses indicated the lack of a group effect on the first 4 test days [all $F \mathrm{~s}(3,16)<1.37, p>.28]$ and a significant effect on the last 2 days [both $F \mathrm{~s}(3,16)>4.51, p<.01$ ]. As is consistent with the depiction in Figure 2, preplanned contrasts indicated that the only significant difference on these 2 days consisted in greater avoidance in the immediate/inflation group than in each of the other groups. Thus, the present differential effect of inflation appears to have been independent of the degree of avoidance or associative strength following conditioning. ${ }^{1}$ Instead, this pattern may reflect a difference in the learning processes underlying avoidance conditioned with an immediate and delay procedure. This result is clearly consistent with the nonassociative account of long-delay taste avoidance, but it is not congruent with the predictions of an associative model.

\section{EXPERIMENT 3}

At an empirical level, these experiments have demonstrated that an intense, postconditioning US-alone trial augments taste avoidance when conditioning occurs with a short CS-US interval but not when it occurs with a long interval. This result suggests that avoidance produced with a long CS-US interval may be due to non- associative learning, since this process should not be influenced by the inflation treatment. However, an interpretation has been proposed for this pattern of results that relies on associative processes alone. Garcia has suggested an explanation for the present effect that incorporates two assumptions concerning the cue dynamics of the $\mathrm{LiCl}$ injection (personal communication, May 16, 1991). He proposed that rats can taste and smell the $\mathrm{LiCl}$ from the injection and that an association is formed between the taste of $\mathrm{LiCl}$ and illness. The temporal relationship of the saccharin and lithium may result in an association between these flavors in the immediate group but not in the delay group. Therefore, associative conditioning mechanisms could be used to explain the present differential inflation effect.

The key feature of this account is the association between the saccharin and lithium tastes occurring in the immediate group. It is this association between the two tastes that allows for the augmentation in avoidance following the inflation injection. The immediate group forms an association between saccharin and lithium taste during the initial pairing, along with a saccharin-illness association. The inflation treatment establishes a strong lithium taste and illness association. Similar to a secondorder conditioning process, the inflation injection acts to augment saccharin avoidance via the previously established taste-taste compound. The long CS-US interval for the delay group prevents a taste-taste association, and thus the inflation injection has no impact on saccharin preference. Therefore, the conditioned response in these animals is simply a function of the CS-US association from the initial long-delay pairing. This analysis not only predicts the present differential inflation effect, but does so with principles of associative conditioning.

The third experiment was designed to assess the possibility that this conditioning process occurred with the 
parameters used in the present series of studies. The critical assumption in the preceding account is that the animals can discriminate a lithium taste from the injection and establish an association between this taste and illness. The question of interest for the present experiments is not whether a rat can taste $\mathrm{LiCl}$ from an injection but rather whether this occurs with the small volume of isotonic $\mathrm{LiCl}$ used. In Experiment 3, we investigated this question by directly measuring consumption of a $\mathrm{LiCl}$ solution following injections of $\mathrm{LiCl}$. If a lithium taste can be associated with illness from a single injection, this should be evidenced by an increased reluctance to drink a $\mathrm{LiCl}$ solution subsequent to the injection. To control for neophobic avoidance and poison-induced enhancement of neophobia, a $2 \times 2$ factorial design was used. After our standard baseline water deprivation period, animals were injected with isotonic $\mathrm{LiCl}$ or $\mathrm{NaCl}$. Although in Experiments 1 and 2 only a single conditioning injection was used, in this experiment animals were injected on two separate sessions. This was done in order to increase the strength of the putative lithium tasteillness association and supply a more conservative test of this potential mechanism. In addition, toxin was injected $4 \mathrm{~h}$ after the daily water drinking period. This procedure was incorporated to avoid a conditioned aversion to the water, which could compromise the test. Two days following this treatment, a two-bottle preference test was conducted between water and one test flavoreither a saccharin solution or $\mathrm{LiCl}$.

\section{Method}

\section{Subjects and Apparatus}

The subjects were 30 adult, male Long-Evans rats from the same stock as was used in the previous experiments. The animals were randomly assigned to each of the four groups. The treatment of animals prior to the start of the present procedure was identical to that previously described.

\section{Procedure}

Baseline water deprivation. The water deprivation and habituation procedures were identical to those used in Experiment 2.

US Preexposure. On Days 7 and 8 , half the animals were injected with $5 \mathrm{ml} / \mathrm{kg}$ of $.15 \mathrm{M} \mathrm{LiCl} 4 \mathrm{~h}$ following the daily water drinking period. The remaining 15 rats served as controls for this US preexposure treatment and were injected with an equivalent volume of isotonic saline. Days 9 and 10 were poison recovery days interposed prior to the test to model the procedure used in the previous experiments and to eliminate poison-induced sensitization of neophobia to the novel test solutions.

Preference test. At the same time of the normal daily water drinking period all animals were given a $30-\mathrm{min}$, two-bottle preference test of water and a test solution. Eight animals from each preexposure group received isotonic $(.15 \mathrm{M}) \mathrm{LiCl}$ as the test solution (identical to that used for US preexposure). The remaining 7 rats in each preexposure group were given a. $1 \%(\mathrm{w} / \mathrm{v})$ solution of sodium saccharin.

\section{Results and Discussion}

In order to obtain a more sensitive measure of conditioned aversions, separate ANOVAs were conducted on the consumption data for the test solutions and the water.
As depicted in Figure 3, there exists a difference as a function of test solution type with no effect of preexposure. The animals from both the $\mathrm{LiCl}$ and the $\mathrm{NaCl}$ preexposure conditions drank less $\mathrm{LiCl}$ solution than did identically treated animals that drank saccharin on the test. The ANOVA revealed a significant main effect of type of test solution $[F(1,26)=11.77]$. The main effect of preexposure drug type and the interaction were both nonsignificant $(F \mathbf{s}<1)$. The water-drinking pattern mirrors the findings for the test solutions. Overall, the only significant finding is a main effect for type of test solution $[F(1,26)=5.25]$. The groups that received $\mathrm{LiCl}$, as a test flavor, drank more water than did the animals that had saccharin as the test solution. This pattern reflects the stability in total fluid consumption and is identical to the pattern that is typically observed with a preference test.

The lack of a $\mathrm{LiCl}$ preexposure effect on the quantity of lithium consumed during the test is inconsistent with the suggestion that the inflation effect stems from a taste of lithium-illness association. Although this finding constitutes a null result and may reflect a problem in sensitivity, it is important, given the results of Experiment 2 . Those data demonstrated a robust taste aversion not only with the same US of the present study, but with only a single pairing and an extremely weak CS $(.005 \%$ $\mathrm{w} / \mathrm{v}$ saccharin). If a $\mathrm{LiCl}$ taste-toxin association is the mechanism for the inflation effect, it should be observable with the parameters of the prior experiments. Moreover, the present test did uncover a main effect of test solution. Thus, the present finding is reasonable evidence against this type of associative mechanism's underlying the differential inflation effect observed in the first two experiments.

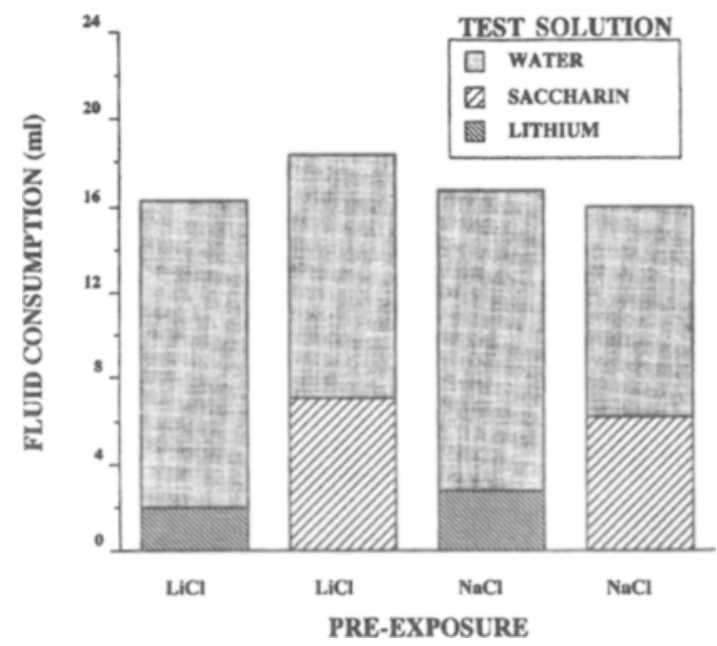

Figure 3. Total amount of fluid drunk during the two-bottle choice test of Experiment 3. The top portion of each bar corresponds to the amount of water drunk in each group. The lower section depicts the quantity of the $\mathrm{LiCl}$ or . $1 \%$ saccharin solution consumed, as a function of type of prior injection. 


\section{GENERAL DISCUSSION}

These experiments represent the first demonstration of a US inflation effect with a conditioned taste-aversion procedure. We also found a limitation on the generality of this inflation effect. In two experiments, we found no effect of the inflation manipulation in animals conditioned with a long delay between the taste and poison. In Experiment 2, we used a CS intensity manipulation which demonstrated that this differential inflation effect was independent of the strength of initial avoidance. It appears that the critical determinant for inflation of a taste aversion is temporal proximity of the CS and US and not associative strength. Thus, evidence for the proposed mechanisms of the nonassociative model is observed while a specific prediction of the associative view is not upheld. Rescorla (1980) has proposed that postconditioning manipulations that modify the expression of a conditional response are effective tools for dissecting the nature of the learning process. Following this logic, the present pattern of results suggests that the learning process underlying the conditioning of immediate and long-delay taste avoidance is different.

The present results, in conjunction with earlier demonstrations of nonassociative influences on flavor conditioning, suggest that there is a difference between the processes responsible for taste avoidance with short and long CS-US intervals. Experiment 2 demonstrated an equivalent avoidance response in the no-inflation immediate and delay groups. However, equality in a behavioral response and function does not imply an equivalent underlying mechanism. Despite the successful equalization of avoidance with the CS intensity manipulation, avoidance in the delay group was not enhanced by the inflation injection. This differential response to the inflation manipulation constitutes strong evidence for different processes. This differential pattern was obtained in two experiments with various saccharin concentrations. In these experiments, the expected neophobic avoidance and habituation were also observed in the animal's response to the novel saccharin solutions. In Experiment 1, neophobic avoidance and habituation can be readily seen in the behavior of the sham controls. A reduction in fluid consumption is obvious on the first saccharin presentation, and the saccharin preference measure shows a steady habituation across the test days in the unpoisoned controls. Although the initial level of saccharin avoidance is greater in the delay groups, the slope of the extinction function appears equivalent to that of the sham controls. This pattern may indicate that the poison reinstated neophobic avoidance but did not affect the further course of neophobic habituation.

The dissociation of the immediate and long-delay procedures by US inflation is reminiscent of the differential effects of postconditioning manipulations observed with first- and second-order conditioning (e.g., Rescorla, 1973, 1974; Rizley \& Rescorla, 1972). Those experiments demonstrated that extinction of the first-order association,
US inflation, and US habituation can all act to modify a first-order CR but do not affect responding to a secondorder stimulus (see, however, Rescorla, 1979). One interpretation of these findings was to distinguish the various conditioning procedures in terms of the nature of the representations, either $\mathrm{S}-\mathrm{S}$ or $\mathrm{S}-\mathrm{R}$, that make up the learned association. Similarly, the differential effect of inflation observed in the present series could arise from a difference in the nature of the conditional representation. An immediate pairing may result in an S-S association, whereas a long CS-US interval may produce an $\mathrm{S}-\mathrm{R}$ association. It is not apparent, however, why these procedures should lead to a different processing of the US. Also, this account does not contribute to an understanding of taste avoidance with long delays or of other phenomena associated with noncontingent poisoning, such as enhanced neophobia (Mitchell et al., 1977). Like the neophobia account, this type of explanation still demands that the learning processes with immediate and delayed taste avoidance are different.

In an effort to understand the dynamics of food selection, many investigators have included various pre- and postconditioning manipulations. Within the taste aversion paradigm, researchers have investigated the effect of CS extinction, US habituation, US preexposure, CS preexposure, and reinstatement (e.g., Bouton, 1982; Colby \& Smith, 1977; Domjan, 1975; Holman, 1976; Jacobs, Zellner, LoLordo, \& Reily, 1981; Schachtman, Brown, \& Miller, 1985). Many of these experimenters have concluded that the processes of conditioned taste aversions are qualitatively similar to other conditioning preparations (Domjan, 1980; Logue, 1979; for an alternative, see Garcia, 1989). This generalist position seems reasonable for taste aversions conditioned with temporally contiguous stimulus events, and many of these experiments have contributed greatly to an understanding of the specific mechanisms underlying both association formation and taste processing. In that regard, the inflation effect observed in the immediate group can be interpreted simply as a product of associative conditioning. However, in none of the experiments above have these tools been used for dissecting the mechanisms underlying long-delay taste avoidance. The present differentiation can contribute more toward a general understanding of the mechanisms of food selection by focusing attention on important nonassociative mechanisms such as neophobia and habituation, rather than the associative approaches that have often constrained theorizing.

\section{REFERENCES}

BARKER, L. M. (1976). CS duration, amount, and concentration effects in conditioned taste aversions. Learning \& Motivation, 7, 265-273.

BaRnet, S. A. (1963). The rat: A study in behavior. Chicago: Aldine. BEST, M. R. (1975). Conditioned and latent inhibition in taste-aversion learning: Clarifying the role of learned safety. Journal of Experimental Psychology: Animal Behavior Processes, 1, 97-113.

Bonardi, C., Guthrie, D., \& Hall, G. (1991). The effect of a retention interval on habituation of the neophobic response. Animal Learning \& Behavior, 19, 11-17. 
Bond, N. [W.], \& DiGiusto, E. [L.] (1975). Amount of solution drunk is a factor in the establishment of taste aversion. Animal Learning \& Behavior, 3, 81-84

Bond, N. W., \& Westbrook, R. F. (1982). The role of amount consumed in flavor preexposure effects and neophobia. Animal Learning \& Behavior, 10, 511-515.

BoUTON, M. E. (1982). Lack of reinstatement of an extinguished taste aversion. Animal Learning \& Behavior, 10, 233-241.

Braun, J. J., \& Rosenthal, B. (1976). Relative salience of saccharin and quinine in long-delay taste aversion learning. Behavioral Biology, 16, 341-352.

Carroll, M. E., Dinc, H. I., Levy, C. J., \& Smith, J. C. (1975). Demonstrations of neophobia and enhanced neophobia in the albino rat. Journal of Comparative \& Physiological Psychology, 89, 457467.

Colby, J. J., \& Smith, N. F. (1977). The effect of three procedures for eliminating a conditioned taste aversion in the rat. Learning \& Motivation, 8, 404-413.

Collier, G., \& Novell, K. (1967). Saccharin as a sugar surrogate. Journal of Comparative \& Physiological Psychology, 64, 404-408.

DEss, N. K. (1993). Saccharin's aversive taste in rats: Evidence and implications. Neuroscience \& Biobehavioral Reviews, 17, 359-372.

Domjan, M. (1975). Poison-induced neophobia in rats: Role of stimulus generalization of conditioned taste aversions. Animal Learning \& Behavior, 3, 205-211.

DomJAN, M. (1977). Selective suppression of drinking during a limited period following aversive drug treatment in rats. Journal of Experimental Psychology: Animal Behavior Processes, 3, 66-76.

DOMJAN, M. (1980). Ingestional aversion learning: Unique and general processes. In J. S. Rosenblatt, R. A. Hinde, C. Beer, \& M. Busnel (Eds.), Advances in the study of behavior (Vol. 11, pp. 275-336). New York: Academic Press.

GarCIA, J. (1978). Mitchell, Scott, and Mitchell are not supported by their own data. Animal Learning \& Behavior, 6, 116.

GARCIA, J. (1989). Food for Tolman: Cognition and cathexis in concert. In T. Archer \& L. Nilsson (Eds.), Aversion, avoidance, and anxiety perspectives on aversively motivated behavior (pp. 45-85). Hillsdale, NJ: Erlbaum.

Garcia, J., ERVIN, F. R., \& Koelling, R. A. (1966). Learning with prolonged delay of reinforcement. Psychonomic Science, 5, 121-122.

GarCIA, J., MCGowaN, B. K., \& GREEN, K. F. (1972). Biological constraints on conditioning. In A. H. Black \& W. F. Prokasy (Eds.), Classical conditioning II: Current research and theory (pp. 21-43). New York: Appleton-Century-Crofts.

GREEN, K. F., \& PARKER, L. A. (1975). Gustatory memory: Incubation and interference. Behavioral Biology, 13, 359-367.

Holman, E. W. (1976). The effect of drug habituation before and after taste aversion learning in rats. Animal Learning \& Behavior, 4, 329332.

JACOBS, W. J., ZELLNER, D. A., LOLORDO, V. M., \& RILEY, A. L. (1981). The effect of post-conditioning exposure to morphine on the retention of a morphine-induced conditioned taste aversion. Pharmacology, Biochemistry \& Behavior, 14, 779-785.

KaLAT, J. W. (1974). Taste salience depends on novelty, not concentration, in taste-aversion learning in the rat. Journal of Comparative \& Physiological Psychology, 86, 47-50.

KALAT, J. W., \& RozIN, P. (1971). Role of interference in taste-aversion learning. Journal of Comparative \& Physiological Psychology, 77, 53-58.

KaLAT, J. W., \& Rozin, P. (1973). "Learned safety" as a mechanism in long-delay taste-aversion learning in rats. Journal of Comparative \& Physiological Psychology, 83, 198-207.

KEPPEL, G. (1982). Design and analysis: A researcher's handbook (2nd ed.). Englewood Cliffs, NJ: Prentice-Hall.

LoGUE, A. W. (1979). Taste aversion and the generality of the laws of learning. Psychological Bulletin, 86, 276-296.

MaCKInTOSH, N. J. (1983). Conditioning and associative learning. New York: Oxford University Press.

Mitchell, D. (1977). Reply to Revusky. Animal Learning \& Behavior, 5, 321-322.

Mitchell, D. (1978). The psychological vs. the ethological rat: Two views of the poison avoidance behavior of the rat compared. Animal Learning \& Behavior, 6, 121-124.

Mitchell, D., Kirschbaum, E. H., \& Perry, R. L. (1975). Effects of neophobia and habituation on the poison-induced avoidance of exteroceptive stimuli in the rat. Journal of Experimental Psychology: Animal Behavior Processes, 1, 47-55.

Mitchell, D., Parker, L. F., \& Johnson, R. (1976). Absence of a generalization decrement in the poison-induced avoidance of interoceptive stimuli in the rat. Physiological Psychology, 4, 121-123.

Mitchell, D., ScotT, D. W., \& Mitchell, L. K. (1977). Attenuated and enhanced neophobia in the taste-aversion "delay of reinforcement" effect. Animal Learning \& Behavior, 5, 99-102.

NaChMan, M., \& JoNES, D. R. (1974). Learned taste aversions over long delays in rats: The role of learned safety. Journal of Comparative \& Physiological Psychology, 86, 949-956.

RESCORLA, R. A. (1973). Effect of US habituation following conditioning. Journal of Comparative \& Physiological Psychology, 82 137-143.

RESCORLA, R. A. (1974). Effect of inflation of the unconditioned stimulus value following conditioning. Journal of Comparative \& Physiological Psychology, 86, 101-106.

RESCORLA, R. A. (1979). Aspects of the reinforcer learned in secondorder Pavlovian conditioning. Journal of Experimental Psychology: Animal Behavior Processes, 5, 70-95.

ResCoRla, R. A. (1980). Pavlovian second-order conditioning: Studies in associative learning. Hillsdale, $\mathrm{NJ}$ : Erlbaum.

REVUSKY, S. H. (1968). Aversion to sucrose produced by contingent Xirradiation. Physiological Psychology, 65, 17-22.

REvUSKY, S. H. (1977). Correction of a paper by Mitchell, Scott, and Mitchell. Animal Learning \& Behavior, 5, 320

Revusky, S. [H.] (1978). Reply to Mitchell. Animal Learning \& Behavior, 6, 119-120.

RevUSKY, S. [H.] (1979). More about appropriate controls for taste aversion learning: A reply to Riley. Animal Learning \& Behavior, 7 , 562-563.

REVUSKY, S. H., \& BEDARF, E. W. (1967). Association of illness with ingestion of novel foods. Science, 155, 219-220.

REVUSKY, S. H., \& GARCIA, J. (1970). Learned associations over long delays. In G. H. Bower \& J. T. Spence (Eds.), Psychology of learning and motivation: Advances in research and theory (Vol. 4, pp. 184). New York: Academic Press.

RICHTER, C. P. (1953)_Experimentally produced behavior reactions to food poisoning in wild and domesticated rats. In R. W. Miner (Ed.), Comparative conditional neuroses (Annals of the New York Academy of Sciences, Vol. 56, pp. 225-239). New York: New York Academy of Sciences.

RILEY, A. L. (1978). In response to and in defense of Mitchell and Revusky: An analysis of nonassociative effects. Animal Learning \& Behavior, 6, 472-473.

RIZley, R. C., \& REscorla, R. A. (1972). Associations in secondorder conditioning and sensory preconditioning. Journal of Comparative \& Physiological Psychology, 81, 1-11.

RozIN, P. (1968). Specific aversions and neophobia resulting from vitamin deficiency or poisoning in half-wild and domestic rats. Journal of Comparative \& Physiological Psychology, 66, 82-88.

RozIN, P., \& KALAT, J. W. (1971). Specific hungers and poison avoidance as adaptive specializations of learning. Psychological Review, 78, 459-486.

RzoskA, J. (1953). Bait shyness: A study in rat behavior. British Journal of Animal Behavior, 1, 128-135.

Schachtman, T. R., Brown, A. M., \& Miller, R. R. (1985). Reinstatement-induced recovery of a taste- $\mathrm{LiCl}$ association following extinction. Animal Learning \& Behavior, 13, 223-227.

SHERMAN, J. E. (1978). US inflation with trace and simultaneous fear conditioning. Animal Learning \& Behavior, 6, 463-468.

Sмiтн, J. C. (1978). Comment on paper by Mitchell, Scott, and Mitchell. Animal Learning \& Behavior, 6, 117-118.

SMith, J. C., \& FosteR, D. F. (1980). Some determinants of intake of glucose + saccharin solutions. Physiology \& Behavior, 25, 127-133.

Smith, J. C., \& Roll, D. L. (1967). Trace conditioning with X-rays as an aversive stimulus. Psychonomic Science, 9, 11-12. 
Young, P. T., \& GREEN, J. T. (1953). Relative acceptability of saccharin solutions as revealed by different methods. Journal of Comparative \& Physiological Psychology, 46, 295-298.

\section{NOTE}

1. The equivalent saccharin preference scores in the no-inflation groups alternatively could reflect an underlying difference in associative strength that is masked by a difference in taste preference. One could argue that the $.005 \%$ solution used in the immediate group was more palatable than the $.2 \%$ solution given to the delay group and that this palatability difference was maintained during testing and obscured a real difference in saccharin aversion. However, a recent review of the saccharin preference literature indicates that this critical assumption regarding palatability is not tenable (Dess, 1993). It has been well documented that weaker saccharin solutions are less palatable than moderate-intensity solutions (e.g., Collier \& Novell, 1967; Smith \& Foster, 1980; Young \& Green, 1953). Each of these reports contains experiments in which various saccharin concentrations were tested in pairs and in isolation. In every case, the experimental evidence indicated peak consumption at intermediate concentrations $(.1 \%-.3 \%)$. Moreover, these concentrations were always preferred over weaker solutions $(.033 \%$ and $.0125 \%)$. Clearly, the conditioning-day saccharin drinking demonstrates greater consumption with the lower concentration. We attribute this to a difference in the initial neophobic response to these two solutions, which is a critical feature of our interpretation. This account is also supported by an additional analysis of first test day saccharin consumption as measured by a change from pretoxicosis consumption. Greater palatability of the weaker saccharin solution masking a stronger CS-US association predicts a differential reduction in saccharin consumption from baseline to test. We analyzed the change in saccharin consumption from baseline to test for the noninflated immediate and delay groups and found that the relative change in consumption was equivalent. The percent change from baseline was $32.18 \%$ $( \pm 12.9)$ for the immediate group and $36.44 \%( \pm 7.4)$ for the delay group. These scores were not significantly different $[F(1,9)=.081]$.

(Manuscript received March 10, 1993; revision accepted for publication July 1, 1994.) 